\title{
Anatomical findings and preservation of transverse sensory branches of the palmar cutaneous nerve during carpal tunnel decompression
}

\author{
Conrad William Lawrence Watters MD FRCSC, Carmen Jadick MD, Phillipe Fleuriau-Chateau MD \\ Section of Plastic Surgery, Ottawa General Hospital, University of Ottawa, Ottawa, Ontario
}

\begin{abstract}
CWL Watters, C Jadick, P Fleuriau-Chateau. Anatomical findings and preservation of transverse sensory branches of the palmar cutaneous nerve during carpal tunnel decompression. Can J Plast Surg 1997;5(2):123-126. Of the possible complications following carpal tunnel release, one of the most distressing to the patient is a painful surgical scar. In this clinical study, 89 hands were examined at the time of surgery in order to identify the precise location, number and size of transverse sensory branches of the median palmar cutaneous nerve (PCN) and to preserve these during the procedure. Without the aid of operating microscope or loupes, a longitudinal interthenar incision was made, followed by careful splitting dissection of the subcutaneous fat. Transverse branches of the PCN, arising from the median nerve, were found in $85.4 \%$ of hands. Both median and ulnar nerve branches were found in $3.4 \%$ of hands, only ulnar nerve branches were found in $1.12 \%$ of hands and no branches were identified in $13.5 \%$ of hands. Multiple branches were found in $32.6 \%$ of cases. On average, these branches crossed the palm $1.5 \mathrm{~cm}$ from the distal wrist crease and were preserved $95 \%$ of the time without the use of operating microscope or loupes. Preservation of these small sensory nerves may prevent neuroma formation and, thereby, reduce the incidence of painful scars following carpal tunnel release.
\end{abstract}

Key Words: Anatomy, Carpal tunnel, Palmar cutaneous nerve, Preservation

Signes anatomiques et préservation des branches sensorielles transverses du nerf cutané palmaire lors de la décompression du tunnel carpien

RÉSUMÉ : Parmi les possibles complications de la décompression des tunnels carpiens, l'une des plus dérangeantes pour le patient est la cicatrice chirurgicale douloureuse. Dans cette étude clinique, 89 mains ont été examinées au moment de la chirurgie afin d'identifier la localisation précise, le nombre et la taille des branches sensorielles transverses du nerf cutané palmaire médian pour les préserver durant l'intervention. Sans l'aide d'un microscope ou d'une loupe durant l'intervention, une incision interthénar longitudinale a été effectuée, suivie d'une dissection soigneuse des tissus adipeux sous-cutanés. Les branches transverses du nerf cutané palmaire originant du nerf médian ont été identifiées dans $85,4 \%$ des mains. Les deux branches médianes et nerveuses cubitales ont été identifiées dans 3,4\% des mains. Seules les branches nerveuses cubitales ont été observées dans moins de $1.12 \%$ des mains et aucune branche n'a été identifiée dans 13,5\% des mains. Les branches multiples ont été identifiées dans 32,6\% des cas. En moyenne, ces branches croisaient la paume à $1,5 \mathrm{~cm}$ du pli distal du poignet et ont été préservées dans une proportion de $95 \%$ sans recours aux microscopes ou aux loupes opératoires. La préservation de ces petits nerfs sensoriels pourrait prévenir la formation de neuromes et ainsi diminuer la fréquence des cicatrices douloureuses après une décompression du tunnel carpien.

$\mathrm{C}$ arpal tunnel release is one of the most common hand operations. Although it is often expected to provide relief, complications such as painful scar and hypesthesia in the area of the scar can persist for six months or more after surgery (1-4). The importance of careful dissection has been previously noted (5-7). Small sensory branches of the median

Correspondence: Dr Conrad WL Watters, 407-2211 Riverside Drive, Ottawa, ON K1H 7X5. Telephone 613-521-1688, fax 613-526-3636, e-maildg902@freenet.carleton.ca palmar cutaneous nerve (PCN) have been noted to cross the palm transversely, intersecting the line of incision in a fairly constant manner (6-11). The suggestion has been made that division of these nerve fibres may lead to neuroma formation and, thus, to hypersensitivity of the scar (6).

Previous reports, based on examination of cadaveric specimens, have provided limited information about the specific number, size and location of these transverse sensory branches of the PCN. Given consistent findings that these branches have not been observed beyond the ulnar axis of the 


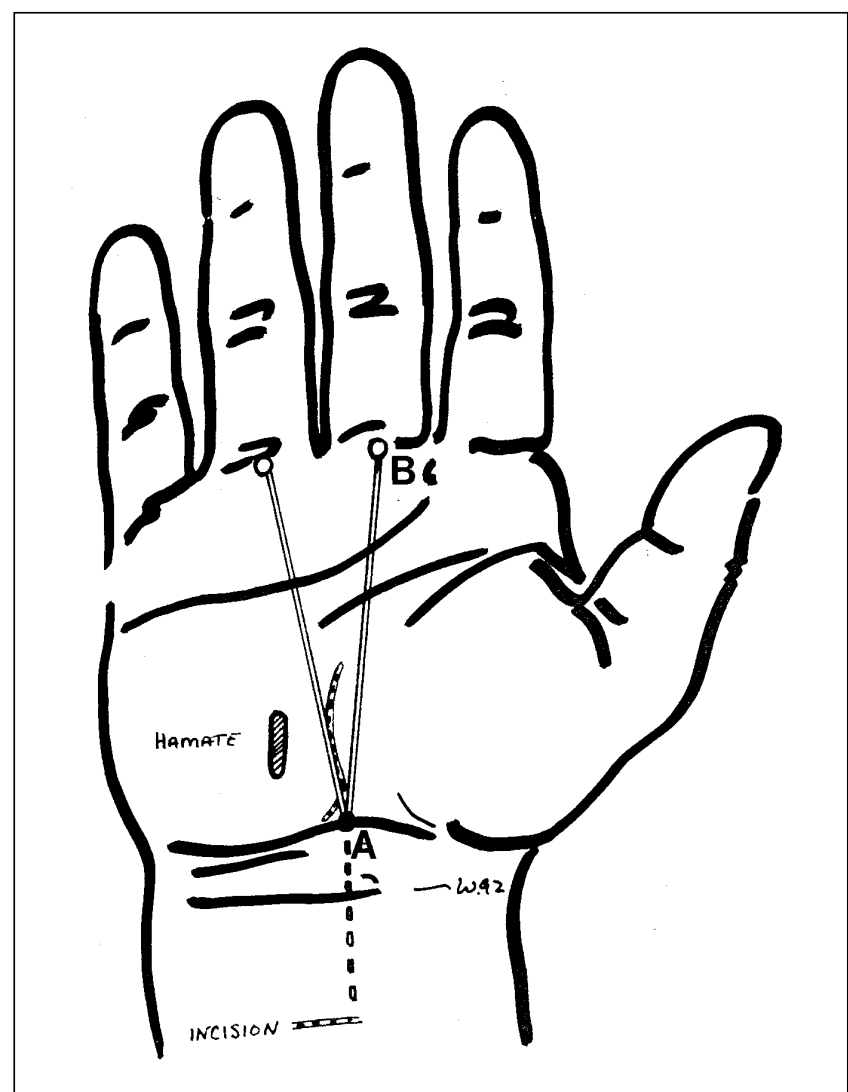

Figure 1) Incision relative to the junction of the palmaris tendon and the distal wrist crease (A). B Junction of the mid-axis of the middle finger and distal palmar crease

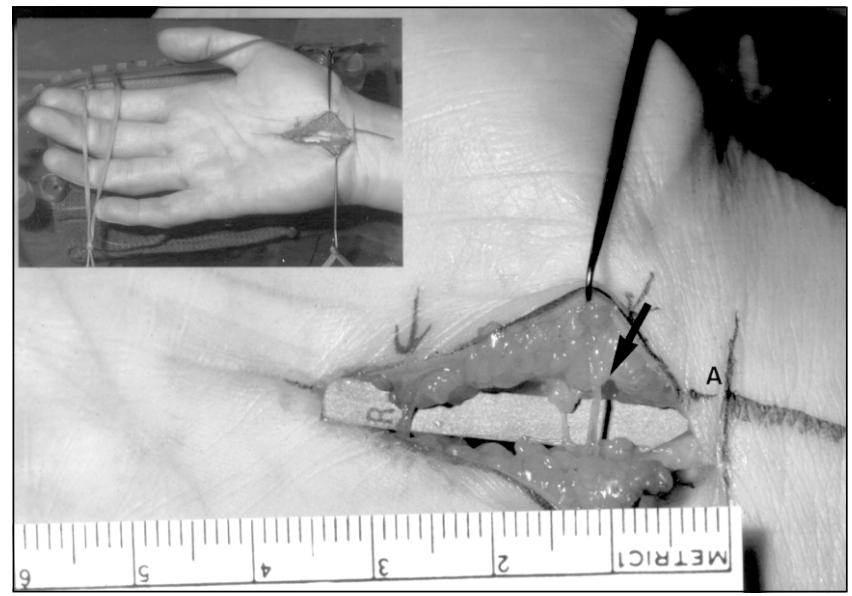

Figure 2) Median palmar cutaneous nerve (arrow). A Junction of the palmaris tendon and the distal wrist crease

ring finger, Taleisnik (6) recommended that the incision be made on the ulnar side of this axis. However, this approach has been criticized because it increases the risk of dividing branches of the ulnar PCN or its transverse fibres, potentially leading to painful neuroma formation (7).

The objectives of this clinical study were to confirm the anatomical findings of previous cadaveric observations about the transverse sensory branches of the median PCN; to de-

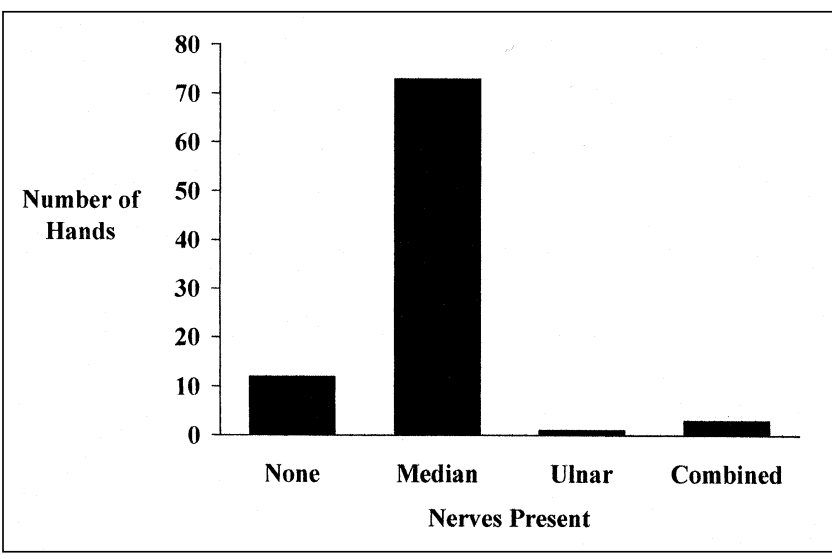

Figure 3) Origin of palmar cutaneous nerve branches

scribe further these nerve fibres with respect to the number, size and specific locations; and to determine whether, by careful dissection during surgery, the sensory fibres can be left intact without diminishing the success of the median nerve decompression.

\section{PATIENTS AND METHODS}

Carpal tunnel decompression surgery was performed on 79 patients: 38 left hands and 53 right hands (total 91 hands). Two of these were repeat operations and therefore excluded from analysis, leaving a total of 89 hands.

Before surgery, a line was drawn from the usual junction of the palmaris longus tendon and the distal wrist crease (A), to the junction of the mid-axis of the middle finger and distal palmar crease (B) (Figure 1). Using tourniquet control, a longitudinal interthenar incision was made while the patient was under intravenous block or local or general anaesthetic. After the skin was incised, small curved tenotomy scissors (Stevens) were used for careful subcutaneous splitting dissection parallel to the nerve fibres, to identify and avoid transection of the nerve branches. This was performed without the aid of loupes or operating microscope (Figure 2).

The origin and location of the nerve branches were measured from point $\mathrm{A}$ along the line $\mathrm{AB}$. Nerve size was graded according to the estimated number of fascicles. The number of branches per hand was also recorded.

\section{RESULTS}

Transverse sensory branches from the median PCN were noted to cross the incision line in 76 out of 89 hands (85.4\%) (Figure 3). Three hands (3.4\%) had transverse branches of both median and ulnar origin. In one case $(1.12 \%)$, only a transverse branch from the ulnar palmar cutaneous branch of the ulnar nerve was identified. No transverse branches were seen in 12 hands $(13.5 \%)$. Two of these hands had ulnarbiased incisions - one over the hamate and one well ulnar to the thenar crease.

With respect to number of branches, $48(54 \%)$ of hands had only one nerve branch identified, 25 (28.1\%) had two branches and four (4.5\%) had three branches (Figure 4). A total of 110 nerves were counted. 


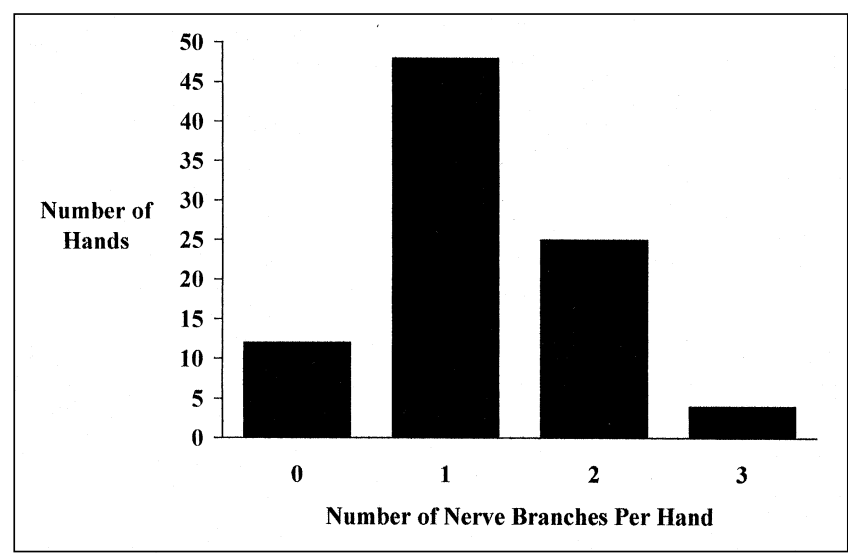

Figure 4) Number of palmar cutaneous nerve branches

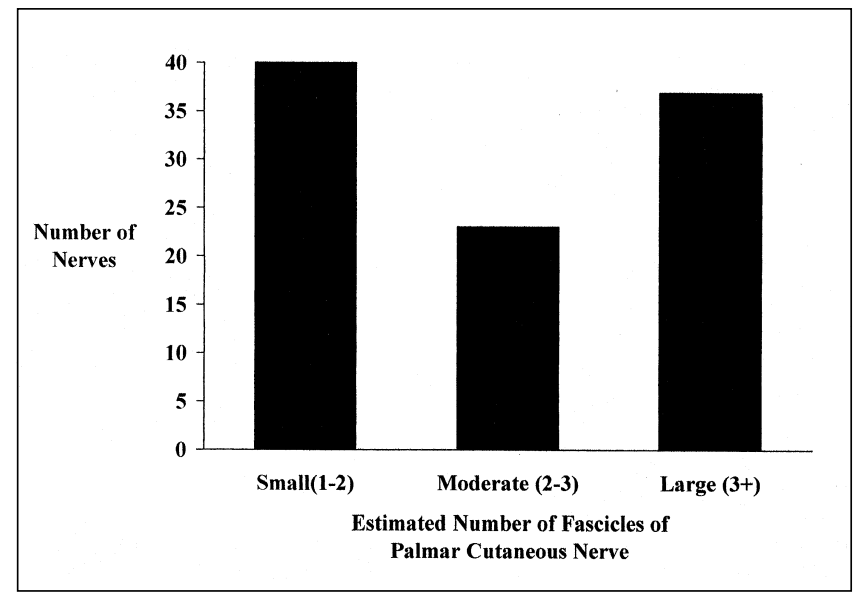

Figure 5) Relative size of palmar cutaneous nerve

The size of 100 of the branches was estimated and categorized (Figure 5). Forty were minor (one to two fascicles), 23 were moderate (two to three fascicles) and 37 were major (more than three fascicles). Moderate and large transverse branches of the median PCN were found, even when the incision was made 3 to $4 \mathrm{~mm}$ ulnar to the axis of the middle finger (six cases) and 6 to $7 \mathrm{~mm}$ ulnar to the same axis (two cases).

The distance from the most distal wrist crease (point A) to the sensory nerve branches ranged from 0.1 to $3.2 \mathrm{~cm}$ (Figure 6 ), with an average distance of $1.5 \mathrm{~cm}$. The majority of the 110 nerves (81 [73.6\%]) were within 1.0 and $2.0 \mathrm{~cm}$ of point A.

In the last 44 hands in this surgical series, observations of the presence of pacinian corpuscles were also documented and were present $50 \%$ of the time ( 22 out of 44 hands).

Nerve branches were left intact in $104(94.5 \%)$ cases and were divided in six (5.4\%). Of these six, three were divided unintentionally. The other three were cut to provide adequate exposure of the carpal tunnel, twice while doing a concomitant synovectomy, and once in an individual with large bulky hands. In all cases, release of the transverse carpal ligament was achieved.

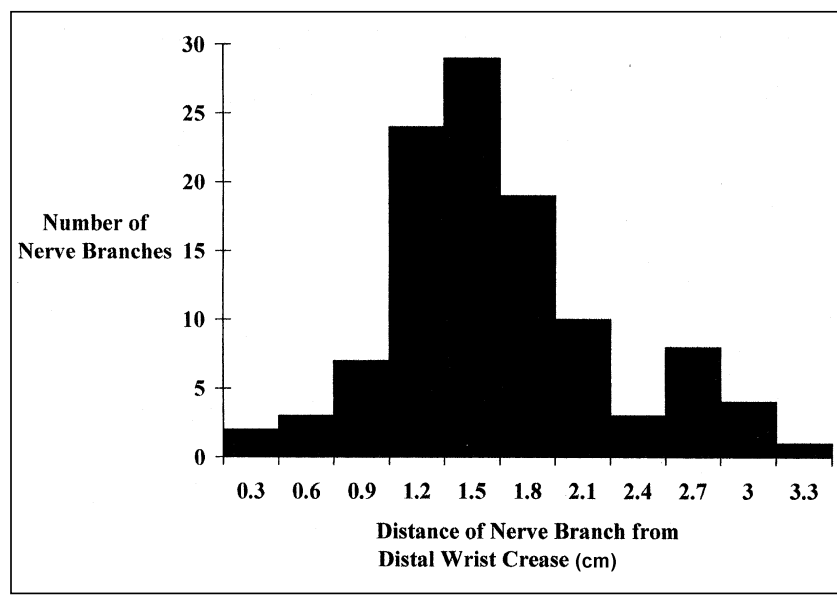

Figure 6) Distance of palmar cutaneous nerve from distal wrist crease

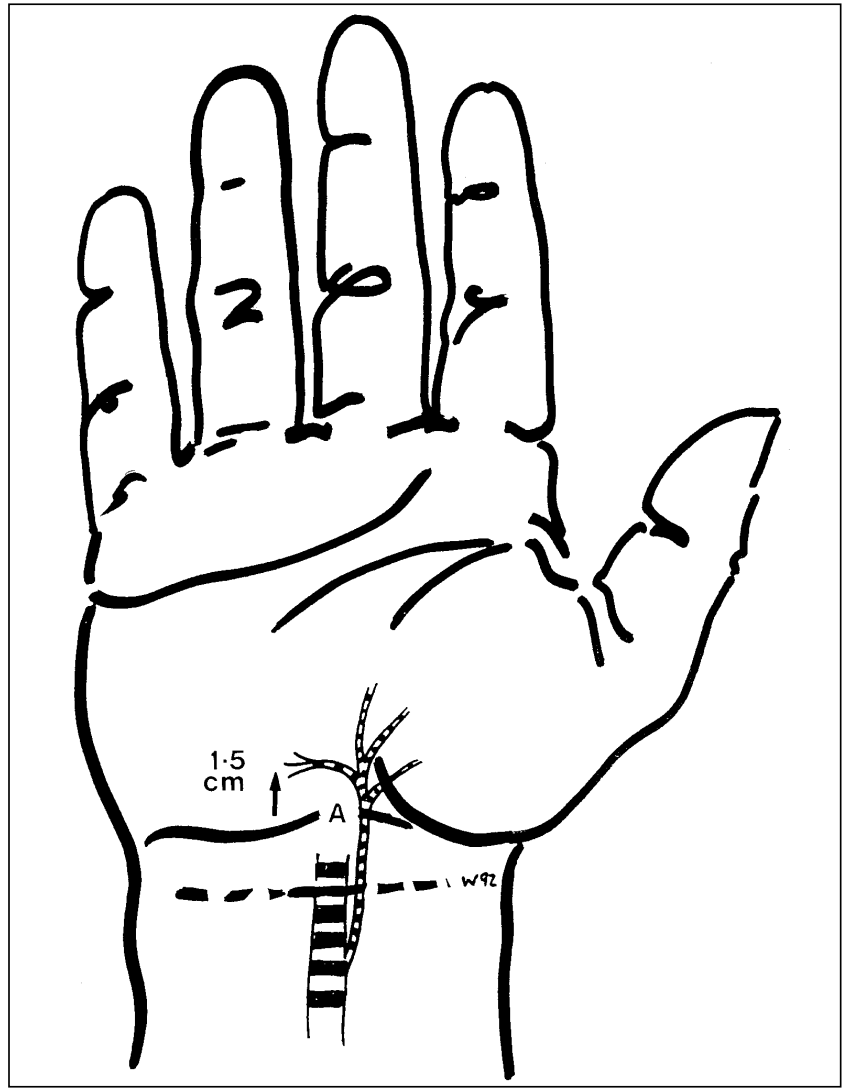

Figure 7) Distance of transverse branch of median palmar cutaneous nerve from junction of the palmaris tendon and the distal wrist crease (A)

\section{DISCUSSION}

During surgery for decompression of carpal tunnel, $85.4 \%$ of hands were found to have transverse sensory branches of the median PCN that crossed the incision line within the subcutaneous tissue. These nerves were consistently found 1 to $2 \mathrm{~cm}$ from the distal wrist crease (average $1.5 \mathrm{~cm}$ ) (Figure 7). Because $60 \%$ of the nerve branches were of moderate or greater size, neuroma formation and subsequent pain or tenderness of the scar could, theoretically, result from transection of 
these superficial nerves. (Note: If scar sensitivity is noted approximately $1.5 \mathrm{~cm}$ from the distal wrist crease after carpal tunnel release, the presence of a neuroma should be strongly suspected.)

These clinical findings generally substantiate previous reports from cadaveric studies about the presence and general location of transverse branches of the median PCN. In 12 dissections, Taleisnik (6) found transverse branches of the median PCN in the subcutaneous tissue of the palm. He noted that none of these branches passed ulnar to the axis of the ray of the ring finger, and he recommended a longitudinal incision on the ulnar side of this axis to reduce the risk of injury, from the usual interthenar incision, to these nerve branches. Others $(8,9)$ describe these nerve branches in more detail and report intermediate branches directed towards the mid-palm of the hand in $100 \%$ of dissections. Median branches approaching the skin of the hypothenar eminence were also found in $42 \%$ to $70 \%$ of specimens $(7,8)$.

Hobbs et al (9), using loupe magnification to dissect 25 fresh specimens, found an average of two, and up to five, ulnar-directed branches of the median PCN distal to the transverse wrist crease. These extended an average of $0.4 \mathrm{~cm}$, and up to $1.0 \mathrm{~cm}$, past the mid-axial line of the hand towards the hypothenar eminence. They did not find any branches passing ulnar to the ring finger axis. Finally, Engber and Gmeiner (7) reported in 21 hand dissections that there were multiple small sensory branches of the PCN supplying the hypothenar skin and extending towards the ring finger axis. Our findings support the cautions of these authors that these branches would be at risk with Taleisnik's incision.

Reports about scar hypersensitivity due to injury of the PCN following carpal tunnel release (1-4) found varying, but significant rates. A review by Kuschner et al (4), reported an incidence of $0.4 \%$ to $5.9 \%$ of injury to the PCN and a $1 \%$ to $23 \%$ incidence of painful scar. Mahoney et al (3), found $51 \%$ scar sensitivity at three months, some of which persisted up to the six-month follow-up.

While this study of live subjects confirms reports from cadaveric studies about sensory branches of the PCN, we have further described the anatomy with respect to number, size and precise location of these nerves. In addition, we also found sensory nerve branches of the median PCN that do cross the axis of the ring finger and overlap with the sensory branches of the ulnar PCN.

These findings therefore confirm speculations that neuroma formation and subsequent scar discomfort can result from transection of these superficial nerves during carpal tunnel release and that the controversy about the ideal location for incision is justified.
However, we have also demonstrated that it is possible to use a surgical technique that uses careful splitting dissection, rather than full-thickness incision, to identify and preserve the majority of these sensory nerve branches. More work is needed, comparing this technique with the more traditional surgical approach, to track the long term outcome for neuroma formation and scar sensitivity.

\section{CONCLUSIONS}

We have demonstrated that by using careful, splitting dissection while noting the anatomy of the branches of the median $\mathrm{PCN}$, it is possible to identify and preserve the majority of the sensory nerve branches without the use of loupes or operating microscope. This surgical technique can potentially reduce morbidity from painful scar and hyperesthesia of the palm due to neuroma formation after carpal tunnel decompression.

ACKNOWLEDGEMENTS: The authors gratefully acknowledge the editorial contributions of Nancy E Watters RN MScN in preparing this paper for publication.

\section{REFERENCES}

1. Das SK, Brown HG. In search of complications in carpal tunnel decompression. The Hand 1976;8:243-9.

2. MacDonald RI, Lichtman DM, Hanlon JJ, Wilson JN. Complications of surgical release for carpal tunnel syndrome. J Hand Surg 1978:3:70-6.

3. Mahoney JL, Lofchy NM, Chow IJS, Hudson A. Carpal tunnel syndrome: A quality assurance evaluation of surgical treatment. Annal CRMCC 1992;25:20-3.

4. Kuschner SH, Brien WW, Johnson D, et al. Complications associated with carpal tunnel release. Orthop Rev 1991;4:346-52.

5. Deutinger M, Zeithofer J, Freilinger G. [Clinical and electroneurographic results following surgery of carpal tunnel syndrome.] Handchir MiKrochir Plast Chir 1987;19:156-60. (Abst, German)

6. Taleisnik J. The palmar cutaneous branch of the median nerve and the approach to the carpal tunnel. J Bone Joint Surg 1973;55(Suppl A): 1212-7.

7. Engber WD, Gmeiner JG. Palmar cutaneous branch of the ulnar nerve. J Hand Surg 1980;5:26-9.

8. Bezerra AJ, Carvalho VC, Nucci A. An anatomical study of the palmar cutaneous branch of the median nerve. Surg Radiol Anat 1986;8:183-8.

9. Hobbs RA, Magnussen PA, Tonkin MA. Palmar cutaneous branch of the median nerve. J Hand Surg 1990;15(Suppl A): 38-43.

10. Lanz U. Anatomical variation of the median nerve in the carpal tunnel. J Hand Surg 1977;2:44-53

11. Carroll RE, Green DP. The significance of the palmar cutaneous nerve at the wrist. Clin Orthop 1972;83:24-8. 